\title{
Convergence of a Viscosity Iterative Method for Multivalued Nonself-Mappings in Banach Spaces
}

\author{
Jong Soo Jung \\ Department of Mathematics, Dong-A University, Busan 604-714, Republic of Korea \\ Correspondence should be addressed to Jong Soo Jung; jungjs@dau.ac.kr
}

Received 9 October 2012; Accepted 9 January 2013

Academic Editor: Yuriy Rogovchenko

Copyright (C) 2013 Jong Soo Jung. This is an open access article distributed under the Creative Commons Attribution License, which permits unrestricted use, distribution, and reproduction in any medium, provided the original work is properly cited.

Let $E$ be a reflexive Banach space having a weakly sequentially continuous duality mapping $J_{\varphi}$ with gauge function $\varphi, C$ a nonempty closed convex subset of $E$, and $T: C \rightarrow \mathscr{K}(E)$ a multivalued nonself-mapping such that $P_{T}$ is nonexpansive, where $P_{T}(x)=\left\{u_{x} \in\right.$ $\left.T x:\left\|x-u_{x}\right\|=d(x, T x)\right\}$. Let $f: C \rightarrow C$ be a contraction with constant $k$. Suppose that, for each $v \in C$ and $t \in(0,1)$, the contraction defined by $S_{t} x=t P_{T} x+(1-t) v$ has a fixed point $x_{t} \in C$. Let $\left\{\alpha_{n}\right\},\left\{\beta_{n}\right\}$, and $\left\{\gamma_{n}\right\}$ be three sequences in $(0,1)$ satisfying approximate conditions. Then, for arbitrary $x_{0} \in C$, the sequence $\left\{x_{n}\right\}$ generated by $x_{n} \in \alpha_{n} f\left(x_{n-1}\right)+\beta_{n} x_{n-1}+\gamma_{n} P_{T}\left(x_{n}\right)$ for all $n \geq 1$ converges strongly to a fixed point of $T$.

\section{Introduction}

Let $E$ be a Banach space and $C$ a nonempty closed subset of $E$. We will denote by $\mathscr{F}(E)$ the family of nonempty closed subsets of $E$, by $\mathscr{C} \mathscr{B}(E)$ the family of nonempty closed bounded subsets of $E$, by $\mathscr{K}(E)$ the family of nonempty compact subsets of $E$, and by $\mathscr{K} \mathscr{C}(E)$ the family of nonempty compact convex subsets of $E$. Let $H(\cdot, \cdot)$ be the Hausdorff distance on $\mathscr{C} \mathscr{B}(E)$; that is,

$$
H(A, B)=\max \left\{\sup _{a \in A} d(a, B), \sup _{b \in B} d(b, A)\right\},
$$

for all $A, B \in \mathscr{C} \mathscr{B}(E)$, where $d(a, B)=\inf \{\|a-b\|: b \in B\}$ is the distance from the point $a$ to the subset $B$. Recall that a mapping $f: C \rightarrow C$ is a contraction on $C$ if there exists a constant $k \in(0,1)$ such that $\|f(x)-f(y)\| \leq k\|x-y\|, x, y \in$ C.

A multivalued mapping $T: C \rightarrow \mathscr{F}(E)$ is said to be a contraction if there exists a constant $k \in[0,1)$ such that

$$
H(T x, T y) \leq k\|x-y\| \quad \forall x, y \in C .
$$

If (2) is valid when $k=1$, the $T$ is called nonexpansive. A point $x$ is a fixed point for a multivalued mapping $T$ if $x \in T x$. Banach's contraction principle was extended to a multivalued contraction by Nadler [1] in 1969. The set of fixed points of $T$ is denoted by $F(T)$.

Given a contraction $f$ with constant $k$ and $t \in(0,1)$, we can define a contraction $G_{t}: C \rightarrow \mathscr{K}(C)$ by

$$
G_{t} x:=t T x+(1-t) f(x), \quad x \in C .
$$

Then $G_{t}$ is a multivalued, and hence it has a (nonunique, in general) fixed point $x_{t}:=x_{t}^{f} \in C$ (see [1]); that is,

$$
x_{t} \in t T x_{t}+(1-t) f\left(x_{t}\right) .
$$

If $T$ is single valued, we have

$$
x_{t}=t T x_{t}+(1-t) f\left(x_{t}\right),
$$

which was studied by Moudafi [2] (see also Xu [3]). As a special case of (5),

$$
x_{t}=t x_{t}+(1-t) \mathrm{u}, \quad \text { for given } u \in C,
$$

has been considered by Browder [4], Halpern [5], Jung and Kim [6, 7], Kim and Takahashi [8], Reich [9], Singh and Watson [10], Takahashi and Kim [11], Xu [12], and Xu and Yin [13] in a Hilbert space and Banach spaces.

In 2007, Jung [14] established the strong convergence of $\left\{x_{t}\right\}$ defined by $x_{t} \in t T x_{t}+(1-t) u, u \in C$ for the multivalued 
nonexpansive nonself-mapping $T$ in a reflexive Banach space having a uniformly Gâteaux differentiable norm under the assumption $T y=\{y\}$.

In order to give a partial answer to Jung's open question [14] Can the assumption Ty $=\{y\}$ be omitted?, in 2008, Shahzad and Zegeye [15] considered a class of multivalued mapping under some mild conditions as follows.

Let $C$ be a closed convex subset of a Banach space $E$. Let $T: C \rightarrow \mathscr{K}(E)$ be a multivalued nonself-mapping and

$$
P_{T} x=\left\{u_{x} \in T x:\left\|x-u_{x}\right\|=d(x, T x)\right\} .
$$

Then $P_{T}: C \rightarrow \mathscr{K}(E)$ is multivalued, and $P_{T} x$ is nonempty and compact for every $x \in C$. Instead of

$$
G_{t} x=t T x+(1-t) u, \quad u \in C,
$$

we consider, for $t \in(0,1)$, that

$$
S_{t} x=t P_{T} x+(1-t) u, \quad u \in C
$$

It is clear that $S_{t} x \subseteq G_{t} x$, and if $P_{T}$ is nonexpansive and $T$ is weakly inward, then $S_{t}$ is weakly inward contraction. Theorem 1 of Lim [16] guarantees that $S_{t}$ has a fixed point, point $x_{t}$; that is,

$$
x_{t} \in t P_{T} x_{t}+(1-t) u \subseteq t T x_{t}+(1-t) u .
$$

If $T$ is single valued, then (10) is reduced to (6).

Shahzad and Zegeye [15] also gave the strong convergence result of $\left\{x_{t}\right\}$ defined by (10) in a reflexive Banach space having a uniformly Gâteaux differentiable norm, which unified, extended, and complemented several known results including those of Jung [14], Jung and Kim [6, 7], Kim and Jung [17], López Acedo and Xu [18], Sahu [19], and Xu and Yin [13].

In 2009, motivated by the results of Rafiq [20] and Yao et al. [21], Ceng and Yao [22] considered the following iterative scheme.

Theorem CY (see [22, Theorem 3.1]). Let E be a uniformly convex Banach space E having a uniformly Gâteaux differentiable norm, $C$ a nonempty closed convex subset of $E$, and $T: C \rightarrow \mathscr{K}(E)$ a multivalued nonself-mapping such that $P_{T}$ is nonexpansive. Suppose that $C$ is a nonexpansive retract of $E$ and that for each $v \in C$ and $t \in(0,1)$ the contraction $S_{t}$ defined by $S_{t} x=t P_{T} x+(1-t) v$ has a fixed point $x_{t} \in C$. Let $\left\{\alpha_{n}\right\},\left\{\beta_{n}\right\}$, and $\left\{\gamma_{n}\right\}$ be three sequences in $(0,1)$ satisfying the following conditions:

(i) $\alpha_{n}+\beta_{n}+\gamma_{n}=1$;

(ii) $\lim _{n \rightarrow \infty} \alpha_{n}=0$ and $\lim _{n \rightarrow \infty}\left(\beta_{n} / \alpha_{n}\right)=0$.

For arbitrary initial value $x_{0} \in C$ and a fixed element $u \in C$, let the sequence $\left\{x_{n}\right\}$ be generated by

$$
x_{n} \in \alpha_{n} u+\beta_{n} x_{n-1}+\gamma_{n} P_{T} x_{n} \quad \forall n \geq 1 .
$$

Then $\left\{x_{n}\right\}$ converges strongly to a fixed point of $T$.
Theorem CY also improves, develops, and complements the corresponding results in Jung [14], Jung and Kim [6, 7], Kim and Jung [17], López Acedo and Xu [18], Shahzad and Zegeye [15], and Xu and Yin [13] to the iterative scheme (11). For convergence of related iterative schemes for several nonlinear mappings, we can refer to [23-26] and the references therein.

In this paper, inspired and motivated by the abovementioned results, we consider a viscosity iterative method for a multivalued nonself-mapping in a reflexive Banach space having a weakly sequentially continuous duality mapping and establish the strong convergence of the sequence generated by the proposed iterative method. Our results improve and develop the corresponding results of Ceng and Yao [22], as well as some known results in the earlier and recent literature, including those of Jung [14], Jung and Kim [6, 7], Kim and Jung [17], López Acedo and Xu [18], Sahu [19], Shahzad and Zegeye [15], Xu [12], and Xu and Yin [13], to the viscosity iterative scheme in different Banach space.

\section{Preliminaries}

Let $E$ be a real Banach space with norm $\|\cdot\|$, and let $E^{*}$ be its dual. The value of $x^{*} \in E^{*}$ at $x \in E$ will be denoted by $\left\langle x, x^{*}\right\rangle$.

A Banach space $E$ is called uniformly convex if $\delta(\varepsilon)>0$ for every $\varepsilon>0$, where the modulus $\delta(\varepsilon)$ of convexity of $E$ is defined by

$\delta(\varepsilon)$

$$
=\inf \left\{1-\left\|\frac{x+y}{2}\right\|:\|x\| \leq 1,\|y\| \leq 1,\|x-y\| \geq \varepsilon\right\}
$$

for every $\varepsilon$ with $0 \leq \varepsilon \leq 2$. It is well known that if $E$ is uniformly convex, then $E$ is reflexive and strictly convex (cf. [27]).

By a gauge function we mean a continuous strictly increasing function $\varphi$ defined on $\mathbb{R}^{+}:=[0, \infty)$ such that $\varphi(0)=0$ and $\lim _{r \rightarrow \infty} \varphi(r)=\infty$. The mapping $J_{\varphi}: E \rightarrow 2^{E^{*}}$ defined by

$$
\begin{array}{r}
J_{\varphi}(x)=\left\{f \in E^{*}:\langle x, f\rangle=\|x\|\|f\|,\|f\|=\varphi(\|x\|)\right\} \\
\forall x \in E
\end{array}
$$

is called the duality mapping with gauge function $\varphi$. In particular, the duality mapping with gauge function $\varphi(t)=t$ denoted by $J$ is referred to as the normalized duality mapping. It is known that a Banach space $E$ is smooth if and only if the normalized duality mapping $J$ is single valued. The following property of duality mapping is also well known:

$$
\begin{aligned}
& J_{\varphi}(\lambda x) \\
& \quad=\operatorname{sign} \lambda\left(\frac{\varphi(|\lambda| \cdot\|x\|)}{\|x\|}\right) J(x) \quad \forall x \in E \backslash\{0\}, \lambda \in \mathbb{R},
\end{aligned}
$$


where $\mathbb{R}$ is the set of all real numbers; in particular, $J(-x)=$ $-J(x)$ for all $x \in E([28])$.

We say that a Banach space $E$ has a weakly sequentially continuous duality mapping if there exists a gauge function $\varphi$ such that the duality mapping $J_{\varphi}$ is single valued and continuous from the weak topology to the weak ${ }^{*}$ topology; that is, for any $\left\{x_{n}\right\} \in E$ with $x_{n} \rightarrow x, J_{\varphi}\left(x_{n}\right) \stackrel{*}{\rightarrow} J_{\varphi}(x)$. For example, every $l^{p}$ space $(1<p<\infty)$ has a weakly continuous duality mapping with gauge function $\varphi(t)=t^{p-1}$. It is well known that if $E$ is a Banach space having a weakly sequentially continuous duality mapping $J_{\varphi}$ with gauge function $\varphi$, then $E$ has the opial condition [29]; this is, whenever a sequence $\left\{x_{n}\right\}$ in $E$ converges weakly to $x \in E$, then

$$
\limsup _{n \rightarrow \infty}\left\|x_{n}-x\right\|<\limsup _{n \rightarrow \infty}\left\|x_{n}-y\right\| \quad \forall y \in E, \quad y \neq x \text {. }
$$

A mapping $T: C \rightarrow \mathscr{C} \mathscr{B}(E)$ is $*$-nonexpansive [30] if, for all $x, y \in C$ and $u_{x} \in T x$ with $\left\|x-u_{x}\right\|=\inf \{\|x-z\|: z \in T x\}$, there exists $u_{y} \in T y$ with $\left\|y-u_{y}\right\|=\inf \{\|y-w\|: w \in T y\}$ such that

$$
\left\|u_{x}-u_{y}\right\| \leq\|x-y\|
$$

It is known that *-nonexpansiveness is different from nonexpansiveness for multivalued mappings. There are some *-nonexpansiveness multivalued mappings which are not nonexpansive and some nonexpansive multivalued mappings which are not $*$-nonexpansive [31].

We introduce some terminology for boundary conditions for nonself-mappings. The inward set of $C$ at $x$ is defined by

$$
I_{C}(x)=\{z \in E: z=x+\lambda(y-x): y \in C, \lambda \geq 0\} .
$$

Let $\bar{I}_{C}(x)=x+T_{C}(x)$ with

$$
T_{C}(x)=\left\{y \in E: \liminf _{\lambda \rightarrow 0^{+}} \frac{d(x+\lambda y, C)}{\lambda}=0\right\}
$$

for any $x \in C$. Note that, for a convex set $C$, we have $\bar{I}_{C}(x)=$ $\overline{I_{C}(x)}$, the closure of $I_{C}(x)$. A multivalued mapping $T: C \rightarrow$ $\mathscr{F}(E)$ is said to satisfy the weak inwardness condition if $T x \subset$ $\bar{I}_{C}(x)$ for all $x \in C$.

Finally, the following lemma was given by $\mathrm{Xu}$ [32] (also see $\mathrm{Xu}[33])$.

Lemma 1. IfC is a closed bounded convex subset of a uniformly convex Banach space $E$ and $T: C \rightarrow \mathscr{K}(E)$ is a nonexpansive mapping satisfying the weak inwardness condition, then $T$ has a fixed point.

\section{Main Results}

Now, we establish strong convergence of a viscosity iterative scheme for a multivalued nonself-mapping.

Theorem 2. Let $E$ be a reflexive Banach space having a weakly sequentially continuous duality mapping $J_{\varphi}$ with gauge function $\varphi$. Let $C$ be a nonempty closed convex subset of $E$ and $T: C \rightarrow \mathscr{K}(E)$ a multivalued nonself-mapping such that $F(T) \neq \emptyset$ and $P_{T}$ is nonexpansive. Let $f: C \rightarrow C$ be a contraction with constant $k$. Suppose that for each $v \in C$ and $t \in(0,1)$, the contraction $S_{t}$ defined by $S_{t} x=t P_{T} x+(1-t) v$ has a fixed point $x_{t} \in C$. Let $\left\{\alpha_{n}\right\},\left\{\beta_{n}\right\}$, and $\left\{\gamma_{n}\right\}$ be three sequences in $(0,1)$ satisfying the following conditions:

(i) $\alpha_{n}+\beta_{n}+\gamma_{n}=1$;

(ii) $\lim _{n \rightarrow \infty} \alpha_{n}=0$ and $\lim _{n \rightarrow \infty}\left(\beta_{n} / \alpha_{n}\right)=0$.

For arbitrary initial value $x_{0} \in C$, let the sequence $\left\{x_{n}\right\}$ be defined by

$$
x_{n} \in \alpha_{n} f\left(x_{n-1}\right)+\beta_{n} x_{n-1}+\gamma_{n} P_{T} x_{n} \quad \forall n \geq 1 .
$$

Then $\left\{x_{n}\right\}$ converges strongly to a fixed point of $T$.

Proof. First, observe that, for each $n \geq 1$,

$$
\begin{aligned}
& \alpha_{n} f\left(x_{n-1}\right)+\beta_{n} x_{n-1} \\
& \quad=\left(1-\gamma_{n}\right)\left(\frac{\alpha_{n}}{1-\gamma_{n}} f\left(x_{n-1}\right)+\frac{\beta_{n}}{1-\gamma_{n}} x_{n-1}\right) .
\end{aligned}
$$

From $x_{n-1}, f\left(x_{n-1}\right) \in C$, it follows that $\left(\alpha_{n} /\left(1-\gamma_{n}\right)\right) f\left(x_{n-1}\right)+$ $\left(\beta_{n} /\left(1-\gamma_{n}\right)\right) x_{n-1} \in C$. Also, notice that, for each $v \in C$ and $t \in(0,1)$, the contraction $S_{t}$ defined by $S_{t} x=t P_{T} x+(1-t) v$ has a fixed point $x_{t} \in C$. Thus, for $\left(\alpha_{n} /\left(1-\gamma_{n}\right)\right) f\left(x_{n-1}\right)+$ $\left(\beta_{n} /\left(1-\gamma_{n}\right)\right) x_{n-1} \in C$ and $\gamma_{n} \in(0,1)$, there exists $x_{n} \in C$ such that

$$
x_{n} \in\left(1-\gamma_{n}\right)\left(\frac{\alpha_{n}}{1-\gamma_{n}} f\left(x_{n-1}\right)+\frac{\beta_{n}}{1-\gamma_{n}} x_{n-1}\right)+\gamma_{n} P_{T}\left(x_{n}\right) \text {. }
$$

This shows that the sequence $\left\{x_{n}\right\}$ can be defined well via the following:

$$
x_{n} \in \alpha_{n} f\left(x_{n-1}\right)+\beta_{n} x_{n-1}+\gamma_{n} P_{T} x_{n} \quad \forall n \geq 1 .
$$

Therefore, for any $n \geq 1$, we can find some $z_{n} \in P_{T}\left(x_{n}\right)$ such that

$$
x_{n}=\alpha_{n} f\left(x_{n-1}\right)+\beta_{n} x_{n-1}+\gamma_{n} z_{n} .
$$

Next, we divide the proof into several steps.

Step 1. We show that $\left\{x_{n}\right\}$ is bounded. Indeed, notice that $P_{T}(y)=\{y\}$ whenever $y$ is a fixed point of $T$. Let $p \in F(T)$. Then $p \in P_{T}(p)$ and we have

$$
\left\|z_{n}-p\right\|=d\left(z_{n}, P_{T}(p)\right) \leq H\left(P_{T}\left(x_{n}\right), P_{T}(p)\right) \leq\left\|x_{n}-p\right\| .
$$

It follows that

$$
\begin{aligned}
\left\|x_{n}-p\right\|= & \left\|\alpha_{n} f\left(x_{n-1}\right)+\beta_{n} x_{n-1}+\gamma_{n} z_{n}-p\right\| \\
\leq & \alpha_{n}\left\|f\left(x_{n-1}\right)-f(p)\right\|+\alpha_{n}\|f(p)-p\| \\
& +\beta_{n}\left\|x_{n-1}-p\right\|+\gamma_{n}\left\|z_{n}-p\right\| \\
\leq & \alpha_{n}\left(k\left\|x_{n-1}-p\right\|+\|f(p)-p\|\right) \\
& +\beta_{n}\left\|x_{n-1}-p\right\|+\gamma_{n}\left\|x_{n}-p\right\|,
\end{aligned}
$$


and so

$$
\begin{aligned}
\left\|x_{n}-p\right\| \leq & \frac{\alpha_{n}}{1-\gamma_{n}}\left(k\left\|x_{n-1}-p\right\|+\|f(p)-p\|\right) \\
& +\frac{\beta_{n}}{1-\gamma_{n}}\left\|x_{n-1}-p\right\| \\
= & \frac{k \alpha_{n}+\beta_{n}}{1-\gamma_{n}}\left\|x_{n-1}-p\right\|+\frac{(1-k) \alpha_{n}}{1-\gamma_{n}} \frac{\|f(p)-p\|}{1-k} \\
\leq & \max \left\{\left\|x_{n-1}-p\right\|, \frac{\|f(p)-p\|}{1-k}\right\} .
\end{aligned}
$$

By induction, we have

$$
\left\|x_{n}-p\right\| \leq \max \left\{\left\|x_{0}-p\right\|, \frac{1}{1-k}\|f(p)-p\|\right\} \quad \text { for } n \geq 1 .
$$

Hence $\left\{x_{n}\right\}$ is bounded and so are $\left\{z_{n}\right\}$ and $\left\{f\left(x_{n}\right)\right\}$.

Step 2. We show that $\lim _{n \rightarrow \infty}\left\|x_{n}-z_{n}\right\|=0$. In fact, since $x_{n}=\alpha_{n} f\left(x_{n-1}\right)+\beta_{n} x_{n-1}+\gamma_{n} z_{n}$ for some $z_{n} \in P_{T}\left(x_{n}\right)$, by conditions (i) and (ii), we have

$$
\begin{array}{r}
\left\|x_{n}-z_{n}\right\| \leq \alpha_{n}\left\|f\left(x_{n-1}\right)-z_{n}\right\|+\beta_{n}\left\|x_{n-1}-z_{n}\right\| \\
\text { as } n \longrightarrow 0
\end{array}
$$

Step 3. We show that there exists $p \in P_{T}(p) \subset T p$. In fact, since $\left\{x_{n}\right\}$ and $\left\{z_{n}\right\}$ are bounded and $E$ is reflexive, there exists a subsequence $\left\{x_{n_{k}}\right\}$ of $\left\{x_{n}\right\}$ such that $x_{n_{k}} \rightarrow p$. For this $p$, by compactness of $P_{T}(p)$, we can find $w_{n} \in P_{T}(p), \forall n \geq 1$, such that

$$
\begin{aligned}
\left\|z_{n}-w_{n}\right\| & =d\left(z_{n}, P_{T}(p)\right) \leq H\left(P_{T}\left(x_{n}\right), P_{T}(p)\right) \\
& \leq\left\|x_{n}-p\right\| .
\end{aligned}
$$

Now suppose that $x_{n}:=x_{n_{k}}$ and $x_{n} \rightarrow p$. The sequence $\left\{w_{n}\right\}$ has a convergent subsequence, which is denoted again by $\left\{w_{n}\right\}$ with $w_{n} \rightarrow w \in P_{T}(p)$. Assume that $w \neq p$. Since a Banach space having the weakly sequentially continuous duality mapping satisfies the opial condition [29], by Step 2, we have

$$
\begin{aligned}
& \limsup _{n \rightarrow \infty}\left\|x_{n}-w\right\| \\
& \quad \leq \limsup _{n \rightarrow \infty}\left(\left\|x_{n}-z_{n}\right\|+\left\|z_{n}-w_{n}\right\|+\left\|w_{n}-w\right\|\right) \\
& \quad \leq \limsup _{n \rightarrow \infty}\left\|z_{n}-w_{n}\right\| \leq \limsup _{n \rightarrow \infty}\left\|x_{n}-p\right\| \\
& \quad<\limsup _{n \rightarrow \infty}\left\|x_{n}-w\right\|,
\end{aligned}
$$

which is a contradiction. Hence we have $w=p$, and so $p=$ $w \in P_{T}(p) \subset T p$.
Step 4. We show that $\lim _{n \rightarrow \infty}\left\langle z_{n}-f\left(x_{n-1}\right), J_{\varphi}\left(x_{n}-y\right)\right\rangle \leq 0$ for $y \in F(T)$. Indeed, for $y \in F(T)$, by (24), we have

$$
\begin{gathered}
\left\langle x_{n}-z_{n}, J_{\varphi}\left(x_{n}-y\right)\right\rangle=\left\langle x_{n}-y+y-z_{n}, J_{\varphi}\left(x_{n}-y\right)\right\rangle \\
\geq\left\|x_{n}-y\right\| \varphi\left(\left\|x_{n}-y\right\|\right)-\left\|z_{n}-y\right\| \varphi\left(\left\|x_{n}-y\right\|\right) \\
\geq\left\|x_{n}-y\right\| \varphi\left(\left\|x_{n}-y\right\|\right)-\left\|x_{n}-y\right\| \varphi\left(\left\|x_{n}-y\right\|\right)=0 .
\end{gathered}
$$

So,

$$
\begin{aligned}
0 \leq & \left\langle x_{n}-z_{n}, J_{\varphi}\left(x_{n}-y\right)\right\rangle \\
= & \alpha_{n}\left\langle f\left(x_{n-1}\right)-z_{n}, J_{\varphi}\left(x_{n}-y\right)\right\rangle \\
& +\beta_{n}\left\langle x_{n-1}-z_{n}, J_{\varphi}\left(x_{n}-y\right)\right\rangle \\
\leq & \alpha_{n}\left(\left\langle f\left(x_{n-1}\right)-z_{n}, J_{\varphi}\left(x_{n}-y\right)\right\rangle\right. \\
& \left.+\frac{\beta_{n}}{\alpha_{n}}\left\|x_{n-1}-z_{n}\right\| \varphi\left(\left\|x_{n}-y\right\|\right)\right) .
\end{aligned}
$$

Thus it follows that

$$
\left\langle z_{n}-f\left(x_{n-1}\right), J_{\varphi}\left(x_{n}-y\right)\right\rangle \leq \frac{\beta_{n}}{\alpha_{n}}\left\|x_{n-1}-z_{n}\right\| \varphi\left(\left\|x_{n}-y\right\|\right) \text {. }
$$

Hence, from condition (ii), we conclude that

$$
\lim _{n \rightarrow \infty}\left\langle z_{n}-f\left(x_{n-1}\right), J_{\varphi}\left(x_{n}-y\right)\right\rangle \leq 0 .
$$

Step 5. We show that $\lim _{n \rightarrow \infty}\left\|x_{n}-p\right\|=0$, where $p$ is defined as in Step 3. Indeed, for $y \in F(T)$,

$$
\begin{aligned}
\left\|x_{n}-y\right\| \varphi\left(\left\|x_{n}-y\right\|\right) & \\
= & \alpha_{n}\left\langle f\left(x_{n-1}\right)-y, J_{\varphi}\left(x_{n}-y\right)\right\rangle \\
& +\beta_{n}\left\langle x_{n-1}-y, J_{\varphi}\left(x_{n}-y\right)\right\rangle+\gamma_{n}\left\langle z_{n}-y, J_{\varphi}\left(x_{n}-y\right)\right\rangle \\
= & \left(\alpha_{n}+\gamma_{n}\right)\left\langle f\left(x_{n-1}\right)-y, J_{\varphi}\left(x_{n}-y\right)\right\rangle \\
& +\frac{\beta_{n}}{\alpha_{n}}\left\langle x_{n-1}-y, J_{\varphi}\left(x_{n}-y\right)\right\rangle \alpha_{n} \\
& +\gamma_{n}\left\langle z_{n}-f\left(x_{n-1}\right), J_{\varphi}\left(x_{n}-y\right)\right\rangle .
\end{aligned}
$$

Interchanging $p$ and $y$ in (35), we obtain

$$
\begin{aligned}
\| x_{n}- & p \| \varphi\left(\left\|x_{n}-p\right\|\right) \\
= & \left(\alpha_{n}+\gamma_{n}\right)\left\langle f\left(x_{n-1}\right)-f(p), J_{\varphi}\left(x_{n}-p\right)\right\rangle \\
& +\left(\alpha_{n}+\gamma_{n}\right)\left\langle f(p)-p, J_{\varphi}\left(x_{n}-p\right)\right\rangle \\
& +\frac{\beta_{n}}{\alpha_{n}}\left\|x_{n-1}-p\right\| \varphi\left(\left\|x_{n}-p\right\|\right) \\
& +\gamma_{n}\left\langle z_{n}-f\left(x_{n-1}\right), J_{\varphi}\left(x_{n}-p\right)\right\rangle,
\end{aligned}
$$


and so

$$
\begin{aligned}
\left(\| x_{n}-\right. & \left.p\|-k\| x_{n-1}-p \|\right) \varphi\left(\left\|x_{n}-p\right\|\right) \\
\leq & \beta_{n} k\left\|x_{n-1}-p\right\| \varphi\left(\left\|x_{n}-p\right\|\right) \\
& +\left(1-\beta_{n}\right)\left\langle f(p)-p, J_{\varphi}\left(x_{n}-p\right)\right\rangle \\
& +\frac{\beta_{n}}{\alpha_{n}}\left\|x_{n-1}-p\right\| \varphi\left(\left\|x_{n}-p\right\|\right) \\
& +\gamma_{n}\left\langle z_{n}-f\left(x_{n-1}\right), J_{\varphi}\left(x_{n}-p\right)\right\rangle .
\end{aligned}
$$

Using the fact that $J_{\varphi}$ is weakly sequentially continuous, Step 4 , and condition (ii), we have

$$
\begin{array}{r}
\left(\left\|x_{n}-p\right\|-k\left\|x_{n-1}-p\right\|\right) \varphi\left(\left\|x_{n}-p\right\|\right) \\
\text { as } n \longrightarrow 0 \\
\longrightarrow \infty .
\end{array}
$$

This implies that $x_{n} \rightarrow p$ as $n \rightarrow \infty$. In fact, if $\lim _{n \rightarrow \infty} \| x_{n}-$ $p \|=\eta \neq 0$, then $\lim _{n \rightarrow \infty} \varphi\left(\left\|x_{n}-p\right\|\right) \neq 0$, and by (38) $\lim _{n \rightarrow \infty}\left(\left\|x_{n}-p\right\|-k\left\|x_{n-1}-p\right\|\right)=0$. This means that $\lim _{n \rightarrow \infty}\left\|x_{n}-p\right\|=\eta=k \eta$, which is a contradiction. Thus we proved that there exists a subsequence $\left\{x_{n_{k}}\right\}$ of $\left\{x_{n}\right\}$ which converges strongly to a fixed point $p$ of $T$.

Step 6. We show that the entire sequence $\left\{x_{n}\right\}$ converges strongly to $p \in F(T)$. Suppose that there exists another subsequence $\left\{x_{n_{j}}\right\}$ of $\left\{x_{n}\right\}$ such that $x_{n_{j}} \rightarrow q$ as $j \rightarrow \infty$. Since $d\left(x_{n_{j}}, P_{T}\left(x_{n_{j}}\right)\right) \leq\left\|x_{n_{j}}-z_{n_{j}}\right\| \rightarrow 0$ as $j \rightarrow \infty$, it follows that $d\left(q, P_{T}(q)\right)=0$ and so $q \in P_{T}(q) \subset T(q)$; that is, $q \in$ $F(T)$. Notice that $P_{T}(q)=\{q\}$. Since $\left\{x_{n}\right\}$ is bounded and the duality mapping $J_{\varphi}$ is single valued and weakly sequentially continuous from $E$ to $E^{*}$, we have

$$
\begin{aligned}
\mid\left\langle x_{n_{j}}-\right. & \left.f(q), J_{\varphi}\left(x_{n_{j}}-p\right)\right\rangle-\left\langle q-f(q), J_{\varphi}(q-p)\right\rangle \mid \\
= & \mid\left\langle x_{n_{j}}-q, J_{\varphi}\left(x_{n_{j}}-p\right)\right\rangle \\
& \quad+\left\langle q-f(q), J_{\varphi}\left(x_{n_{j}}-p\right)-J_{\varphi}(q-p)\right\rangle \mid \\
\leq & \left\|x_{n_{j}}-q\right\| \varphi\left(\left\|x_{n_{j}}-p\right\|\right) \\
& +\left|\left\langle q-f(q), J_{\varphi}\left(x_{n_{j}}-p\right)-J_{\varphi}(q-p)\right\rangle\right| \\
\longrightarrow & 0 \text { as } j \longrightarrow \infty .
\end{aligned}
$$

Thus, from Steps 2 and 4, it follows that

$$
\begin{aligned}
\langle q & \left.-f(q), J_{\varphi}(q-p)\right\rangle \\
= & \lim _{j \rightarrow \infty}\left\langle x_{n_{j}}-f(q), J_{\varphi}\left(x_{n_{j}}-p\right)\right\rangle \\
= & \lim _{j \rightarrow \infty}\left\langle x_{n_{j}}-z_{n_{j}}, J_{\varphi}\left(x_{n_{j}}-p\right)\right\rangle \\
& +\lim _{j \rightarrow \infty}\left\langle z_{n_{j}}-f\left(x_{n_{j}-1}\right), J_{\varphi}\left(x_{n_{j}}-p\right)\right\rangle \\
& +\lim _{j \rightarrow \infty}\left\langle f\left(x_{n_{j}-1}\right)-f(q), J_{\varphi}\left(x_{n_{j}}-p\right)\right\rangle \\
\leq & \left\|x_{n_{j}}-z_{n_{j}}\right\| \varphi\left(\left\|x_{n_{j}}-p\right\|\right) \\
& +k \lim _{j \rightarrow \infty}\left\|x_{n_{j}-1}-q\right\| \varphi\left(\left\|x_{n_{j}}-p\right\|\right) \\
& +\lim _{j \rightarrow \infty}\left\langle z_{n_{j}}-f\left(x_{n_{j}-1}\right), J_{\varphi}\left(x_{n_{j}}-p\right)\right\rangle \leq 0 .
\end{aligned}
$$

By the same argument, we also have

$$
\left\langle p-f(p), J_{\varphi}(p-q)\right\rangle \leq 0 .
$$

Therefore, from (40) and (41), we obtain

$$
\begin{aligned}
\|p-q\| \varphi(\|p-q\|) \\
=\left\langle p-q, J_{\varphi}(p-q)\right\rangle \\
=\left\langle p-f(p), J_{\varphi}(p-q)\right\rangle \\
+\left\langle f(p)-f(q), J_{\varphi}(p-q)\right\rangle \\
+\left\langle q-f(q), J_{\varphi}(q-p)\right\rangle \\
\leq\left\langle f(p)-f(q), J_{\varphi}(p-q)\right\rangle \\
\leq k\|p-q\| \varphi(\|p-q\|),
\end{aligned}
$$

and so $(1-k)\|p-q\| \varphi(\|p-q\|) \leq 0$. Thus $p=q$. This completes the proof.

Remark 3. (1) In Theorem 2, if $f(x)=u \in C, x \in E$, is a constant mapping, then the iterative scheme (19) is reduced to the iterative scheme (11) in Theorem CY of Ceng and Yao [22] in the Introduction section. Therefore Theorem 2 improves Theorem CY to the viscosity iterative scheme in different Banach space.

(2) In Theorem 2, we remove the assumption that $C$ is a nonexpansive retract of $E$ in Theorem CY.

(3) In Theorem 2, if $\beta_{n}=0$ for $n \geq 0$, then the iterative scheme (19) becomes the following scheme:

$$
x_{n} \in \alpha_{n} f\left(x_{n-1}\right)+\left(1-\alpha_{n}\right) P_{T}\left(x_{n}\right),
$$

which is a viscosity iterative scheme for those in Shahzad and Zegeye [15]. Therefore Theorem 2 develops Theorem 3.1 of 
Shahzad and Zegeye [15], as well as Theorem 1 of Jung [14], to the viscosity iterative method in different Banach space.

(4) Theorem 2 also improves and complements the corresponding results of Kim and Jung [17] and Sahu [19] as well as Jung and Kim [6,7], López Acedo and $\mathrm{Xu}[18]$, and $\mathrm{Xu}$ and Yin [13].

By definition of the Hausdorff metric, we obtain that if $T$ is *-nonexpansive, then $P_{T}$ is nonexpansive. Hence, as a direct consequence of Theorem 2, we have the following result.

Corollary 4. Let $E$ be a reflexive Banach space having a weakly sequentially continuous duality mapping $J_{\varphi}$ with gauge function $\varphi$. Let $C$ be a nonempty closed convex subset of $E$ and $T: C \rightarrow \mathscr{K}(E)$ a multivalued $*$-nonexpansive nonselfmapping such that $F(T) \neq \emptyset$. Let $f: C \rightarrow C$ be a contraction with constant $k$. Suppose that, for each $v \in C$ and $t \in(0,1)$, the contraction $S_{t}$ defined by $S_{t} x=t P_{T} x+(1-t) v$ has a fixed point $x_{t} \in C$. Let $\left\{\alpha_{n}\right\},\left\{\beta_{n}\right\}$, and $\left\{\gamma_{n}\right\}$ be three sequences in $(0,1)$ satisfying the following conditions:

(i) $\alpha_{n}+\beta_{n}+\gamma_{n}=1$;

(ii) $\lim _{n \rightarrow \infty} \alpha_{n}=0$ and $\lim _{n \rightarrow \infty}\left(\beta_{n} / \alpha_{n}\right)=0$.

For arbitrary initial value $x_{0} \in C$, let the sequence $\left\{x_{n}\right\}$ be generated by (19). Then $\left\{x_{n}\right\}$ converges strongly to a fixed point of $T$.

It is well known that every nonempty closed convex subset $C$ of a strictly convex and reflexive Banach space $E$ is Chebyshev; that is, for any $x \in E$, there is a unique element $u \in C$ such that $\|x-u\|=\inf \{\|x-v\|: v \in C\}$. Thus, we have the following corollary.

Corollary 5. Let E be a strictly convex and reflexive Banach space having a weakly sequentially continuous duality mapping $J_{\varphi}$ with gauge function $\varphi$. Let $C$ be a nonempty closed convex subset of $E$ and $T: C \rightarrow \mathscr{K} \mathscr{C}(E)$ a multivalued nonselfmapping such that $F(T) \neq \emptyset$ and $P_{T}$ is nonexpansive. Let $f$ : $C \rightarrow C$ be a contraction with constant $k$. Suppose that, for each $v \in C$ and $t \in(0,1)$, the contraction $S_{t}$ defined by $S_{t} x=t P_{T} x+(1-t) v$ has a fixed point $x_{t} \in C$. Let $\left\{\alpha_{n}\right\},\left\{\beta_{n}\right\}$, and $\left\{\gamma_{n}\right\}$ be three sequences in $(0,1)$ satisfying the following conditions:

(i) $\alpha_{n}+\beta_{n}+\gamma_{n}=1$;

(ii) $\lim _{n \rightarrow \infty} \alpha_{n}=0$ and $\lim _{n \rightarrow \infty}\left(\beta_{n} / \alpha_{n}\right)=0$.

For arbitrary initial value $x_{0} \in C$, let the sequence $\left\{x_{n}\right\}$ be generated by (19). Then $\left\{x_{n}\right\}$ converges strongly to a fixed point of $T$.

Proof. In this case, $T x$ is Chebyshev for each $x \in C$. So $P_{T}$ is a selector of $T$ and $P_{T}$ is single valued. Thus the result follows from Theorem 2 .

Corollary 6. Let $E$ be a strictly convex and reflexive Banach space having a weakly sequentially continuous duality mapping $J_{\varphi}$ with gauge function $\varphi$. Let $C$ be a nonempty closed convex subset of $E$ and $T: C \rightarrow \mathscr{K} \mathscr{C}(E)$ a multivalued $*$-nonexpansive nonself-mapping such that $F(T) \neq \emptyset$. Let $f: C \rightarrow C$ be a contraction with constant $k$. Suppose that, for each $v \in C$ and $t \in(0,1)$, the contraction $S_{t}$ defined by $S_{t} x=t P_{T} x+(1-t) v$ has a fixed point $x_{t} \in C$. Let $\left\{\alpha_{n}\right\},\left\{\beta_{n}\right\}$, and $\left\{\gamma_{n}\right\}$ be three sequences in $(0,1)$ satisfying the following conditions:

(i) $\alpha_{n}+\beta_{n}+\gamma_{n}=1$;

(ii) $\lim _{n \rightarrow \infty} \alpha_{n}=0$ and $\lim _{n \rightarrow \infty}\left(\beta_{n} / \alpha_{n}\right)=0$.

For arbitrary initial value $x_{0} \in C$, let the sequence $\left\{x_{n}\right\}$ be generated by (19). Then $\left\{x_{n}\right\}$ converges strongly to a fixed point of $T$.

Corollary 7. Let E be a uniformly convex Banach space having a weakly sequentially continuous duality mapping $J_{\varphi}$ with gauge function $\varphi$. Let $C$ be a nonempty closed convex subset of $E$ and $T: C \rightarrow \mathscr{K}(E)$ a multivalued nonself-mapping satisfying the weak inwardness condition such that $P_{T}$ is nonexpansive. Let $f: C \rightarrow C$ be a contraction with constant $k$. Let $\left\{\alpha_{n}\right\},\left\{\beta_{n}\right\}$, and $\left\{\gamma_{n}\right\}$ be three sequences in $(0,1)$ satisfying the following conditions:

$$
\begin{aligned}
& \text { (i) } \alpha_{n}+\beta_{n}+\gamma_{n}=1 \text {; } \\
& \text { (ii) } \lim _{n \rightarrow \infty} \alpha_{n}=0 \text { and } \lim _{n \rightarrow \infty}\left(\beta_{n} / \alpha_{n}\right)=0 \text {. }
\end{aligned}
$$

For arbitrary initial value $x_{0} \in C$, let the sequence $\left\{x_{n}\right\}$ be generated by (19). Then $\left\{x_{n}\right\}$ converges strongly to a fixed point of $T$.

Proof. Define, for each $v \in C$ and $t \in(0,1)$, the contraction $S_{t}: C \rightarrow \mathscr{K}(E)$ by

$$
S_{t} x:=t P_{T} x+(1-t) v, \quad x \in C .
$$

As it is easily seen that $S_{t}$ also satisfies the weak inwardness condition: $S_{t} x \subset \bar{I}_{C}(x)$ for all $x \in C$, it follows from Lemma 1 that $S_{t}$ has a fixed point denoted by $x_{t}$. Thus the result follows from Theorem 2 .

Remark 8. (1) As in [31], Shahzad and Zegeye [15] gave the following example of a multivalued $T$ such that $P_{T}$ is nonexpansive. Let $C=[0, \infty)$, and let $T$ be defined by $T x=$ $[x, 2 x]$ for $x \in C$. Then $P_{T} x=\{x\}$ for $x \in C$. Also $T$ is $*-$ nonexpansive but not nonexpansive (see [31]).

(2) Corollaries 4-7 develop Corollaries 3.3-3.6 of Ceng and Yao [22] to the viscosity iterative method in different Banach spaces.

(3) By replacing the iterative scheme (11) in Theorem CY with the iterative scheme (19) in Theorem 2 and using the same proof lines as Theorem CY together with our method, we can also establish the viscosity iteration version of Theorem CY.

\section{Acknowledgments}

The author thanks the anonymous referees for their valuable comments and suggests, which improved the presentation of this paper and for providing some recent related papers. This research was supported by Basic Science Research Program 
through the National Research Foundation of Korea (NRF) funded by the Ministry of Education, Science and Technology (2012000895).

\section{References}

[1] S. B. Nadler, Jr., "Multi-valued contraction mappings," Pacific Journal of Mathematics, vol. 30, pp. 475-488, 1969.

[2] A. Moudafi, "Viscosity approximation methods for fixed-points problems," Journal of Mathematical Analysis and Applications, vol. 241, no. 1, pp. 46-55, 2000.

[3] H. K. Xu, "Viscosity approximation methods for nonexpansive mappings," Journal of Mathematical Analysis and Applications, vol. 298, no. 1, pp. 279-291, 2004.

[4] F. E. Browder, "Convergence of approximants to fixed points of nonexpansive non-linear mappings in Banach spaces," Archive for Rational Mechanics and Analysis, vol. 24, pp. 82-90, 1967.

[5] B. Halpern, "Fixed points of nonexpanding maps," Bulletin of the American Mathematical Society, vol. 73, pp. 957-961, 1967.

[6] J. S. Jung and S. S. Kim, "Strong convergence theorems for nonexpansive nonself-mappings in Banach spaces," Nonlinear Analysis: Theory, Methods \& Applications, vol. 33, no. 3, pp. 321329, 1998.

[7] J. S. Jung and T. H. Kim, "Strong convergence of approximating fixed points for nonexpansive nonself-mappings in Banach spaces," Kodai Mathematical Journal, vol. 21, no. 3, pp. 259-272, 1998.

[8] G. E. Kim and W. Takahashi, "Strong convergence theorems for nonexpansive nonself-mappings in Banach spaces," Nihonkai Mathematical Journal, vol. 7, no. 1, pp. 63-72, 1996.

[9] S. Reich, "Strong convergence theorems for resolvents of accretive operators in Banach spaces," Journal of Mathematical Analysis and Applications, vol. 75, no. 1, pp. 287-292, 1980.

[10] S. P. Singh and B. Watson, "On approximating fixed points," Proceedings of Symposia in Pure Mathematics, vol. 45, no. 2, pp. 393-395, 1988.

[11] W. Takahashi and G. E. Kim, "Strong convergence of approximants to fixed points of nonexpansive nonself-mappings in Banach spaces," Nonlinear Analysis: Theory, Methods \& Applications, vol. 32, no. 3, pp. 447-454, 1998.

[12] H. K. Xu, "Approximating curves of nonexpansive nonselfmappings in Banach spaces," Comptes Rendus de l'Académie des Sciences, Série I, vol. 325, no. 2, pp. 151-156, 1997.

[13] H. K. Xu and X. M. Yin, "Strong convergence theorems for nonexpansive non-self-mappings," Nonlinear Analysis: Theory, Methods \& Applications, vol. 24, no. 2, pp. 223-228, 1995.

[14] J. S. Jung, "Strong convergence theorems for multivalued nonexpansive nonself-mappings in Banach spaces," Nonlinear Analysis: Theory, Methods \& Applications, vol. 66, no. 11, pp. 2345-2354, 2007.

[15] N. Shahzad and H. Zegeye, "Strong convergence results for nonself multimaps in Banach spaces," Proceedings of the American Mathematical Society, vol. 136, no. 2, pp. 539-548, 2008.

[16] T. C. Lim, "A fixed point theorem for weakly inward multivalued contractions," Journal of Mathematical Analysis and Applications, vol. 247, no. 1, pp. 323-327, 2000.

[17] T. H. Kim and J. S. Jung, "Approximating fixed points of nonlinear mappings in Banach spaces," in Proceedings of the Workshop on Fixed Point Theory (Kazimierz Dolny, 1997), vol. 51, no. 2, pp. 149-165, 1997.
[18] G. López Acedo and H. K. Xu, "Remarks on multivalued nonexpansive mappings," Soochow Journal of Mathematics, vol. 21, no. 1, pp. 107-115, 1995.

[19] D. R. Sahu, "Strong convergence theorems for nonexpansive type and non-self-multi-valued mappings," Nonlinear Analysis: Theory, Methods \& Applications, vol. 37, no. 3, pp. 401-407, 1999.

[20] A. Rafiq, "On Mann iteration in Hilbert spaces," Nonlinear Analysis: Theory, Methods \& Applications, vol. 66, no. 10, pp. 2230-2236, 2007.

[21] Y. Yao, Y. C. Liou, and R. Chen, "Strong convergence of an iterative algorithm for pseudocontractive mapping in Banach spaces," Nonlinear Analysis: Theory, Methods \& Applications, vol. 67, no. 12, pp. 3311-3317, 2007.

[22] L. C. Ceng and J. C. Yao, "Strong convergence of an iterative algorithm for nonself multimaps in Banach spaces," Nonlinear Analysis: Theory, Methods \& Applications, vol. 71, no. 10, pp. 4476-4485, 2009.

[23] Y. Alber, S. Reich, and J. C. Yao, "Iterative methods for solving fixed-point problems with nonself-mappings in Banach spaces," Abstract and Applied Analysis, vol. 2003, no. 4, pp. 193-216, 2003, Proceedings of the International Conference on Fixed Point Theory and its Applications.

[24] L. C. Ceng, A. Petruşel, and J. C. Yao, "Iterative approximation of fixed points for asymptotically strict pseudocontractive type mappings in the intermediate sense," Taiwanese Journal of Mathematics, vol. 15, no. 2, pp. 587-606, 2011.

[25] A. Petruşel and J. C. Yao, "Viscosity approximation to common fixed points of families of nonexpansive mappings with generalized contractions mappings," Nonlinear Analysis: Theory, Methods \& Applications, vol. 69, no. 4, pp. 1100-1111, 2008.

[26] W. Takahashi, J. C. Yao, and P. Kocourek, "Weak and strong convergence theorems for generalized hybrid nonself-mappings in Hilbert spaces," Journal of Nonlinear and Convex Analysis, vol. 11, no. 3, pp. 567-586, 2010.

[27] K. Goebel and S. Reich, Uniform Convexity, Hyperbolic Geometry, and Nonexpansive Mappings, vol. 83 of Monographs and Textbooks in Pure and Applied Mathematics, Marcel Dekker, New York, NY, USA, 1984.

[28] I. Cioranescu, Geometry of Banach Spaces, Duality Mappings and Nonlinear Problems, vol. 62 of Mathematics and Its Applications, Kluwer Academic, Dordrecht, The Netherlands, 1990.

[29] K. Goebel and W. A. Kirk, Topics in Metric Fixed Point Theory, vol. 28 of Cambridge Studies in Advanced Mathematics, Cambridge University Press, Cambridge, UK, 1990.

[30] T. Husain and A. Latif, "Fixed points of multivalued nonexpansive maps," Mathematica Japonica, vol. 33, no. 3, pp. 385-391, 1988.

[31] H. K. Xu, "On weakly nonexpansive and *-nonexpansive multivalued mappings," Mathematica Japonica, vol. 36, no. 3, pp. 441-445, 1991.

[32] H. K. Xu, "Multivalued nonexpansive mappings in Banach spaces," Nonlinear Analysis: Theory, Methods \& Applications, vol. 43, no. 6, pp. 693-706, 2001.

[33] H. K. Xu, "Metric fixed point theory for multivalued mappings," Dissertationes Mathematicae (Rozprawy Matematyczne), vol. 389, p. 39, 2000. 


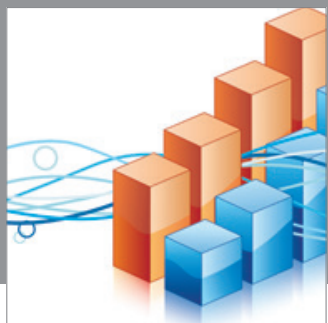

Advances in

Operations Research

mansans

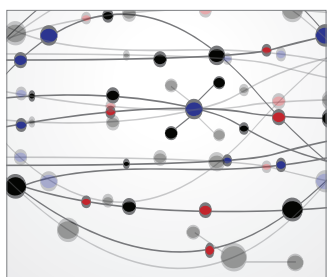

The Scientific World Journal
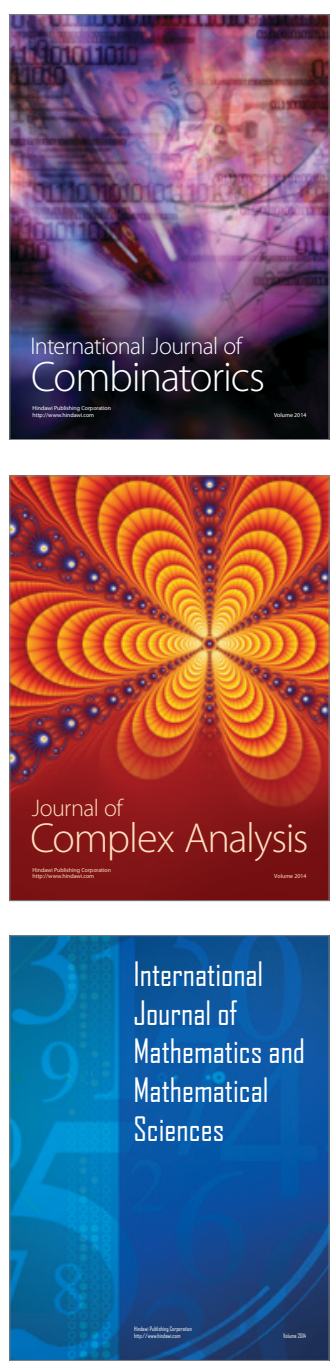
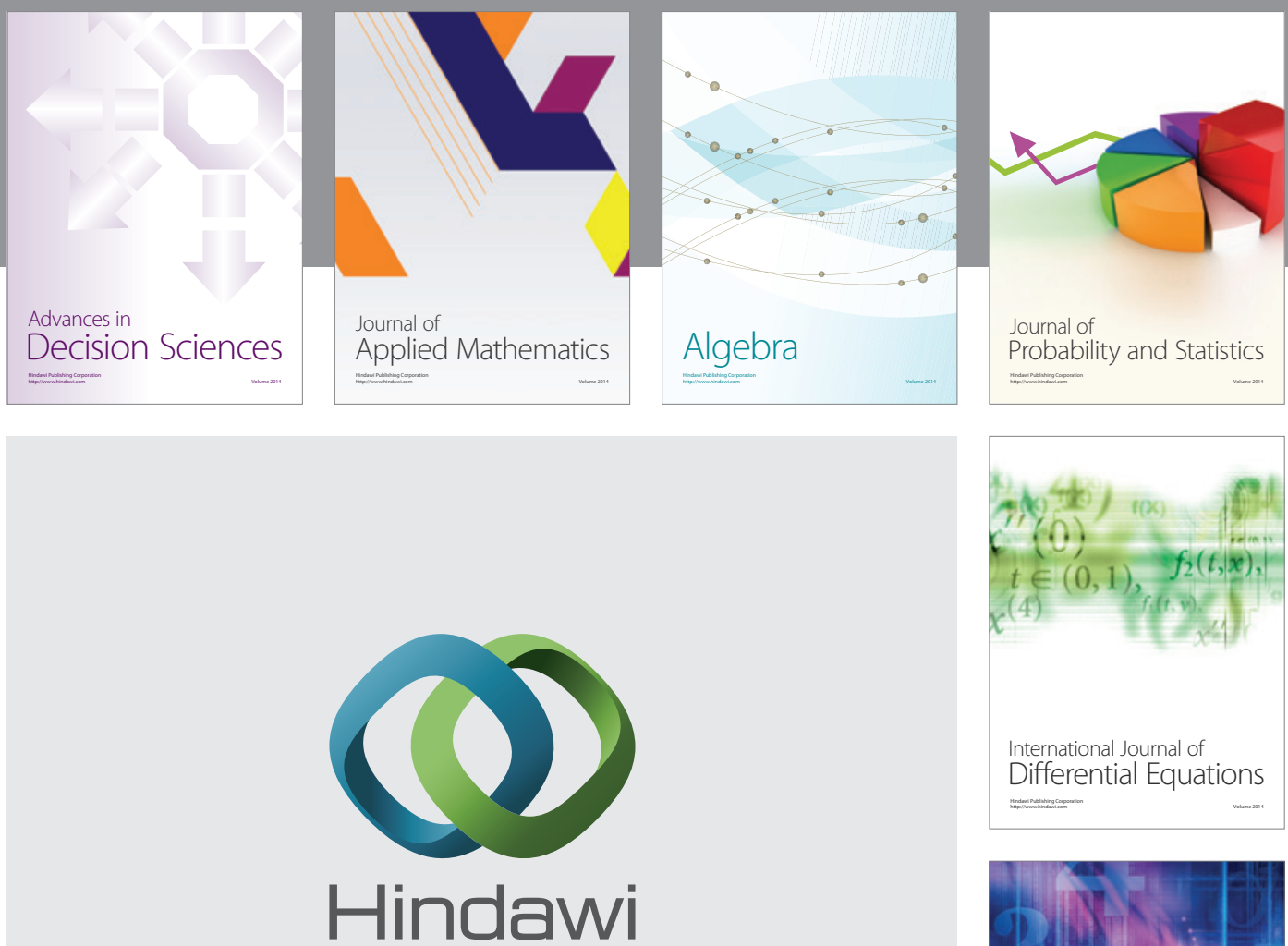

Submit your manuscripts at http://www.hindawi.com
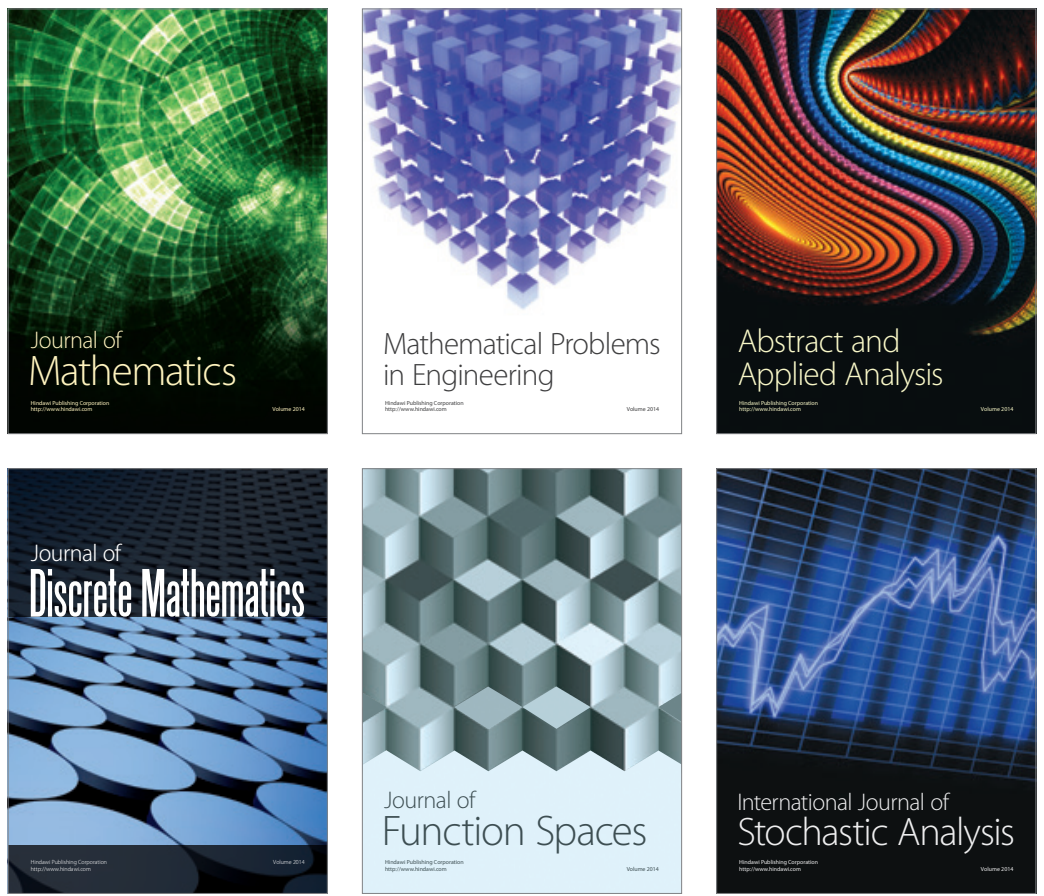

Journal of

Function Spaces

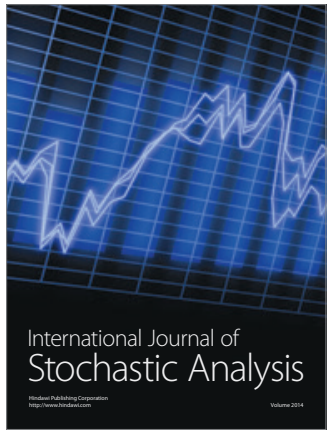

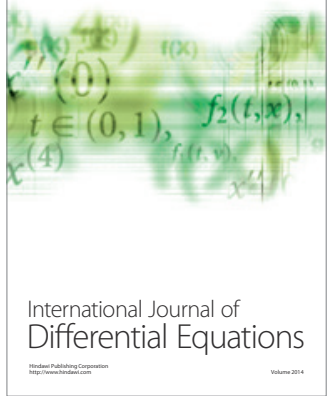
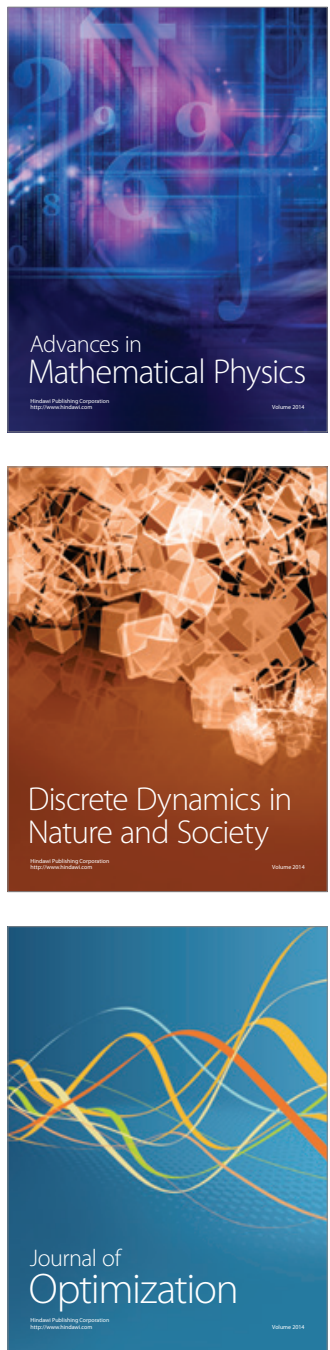